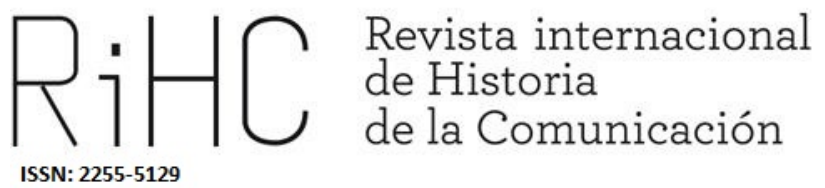

\title{
LA REVISTA RESSORGIMENT Y LA COLECTIVIDAD CATALANA DE BUENOS AIRES (1916-1946)
}

The magazin Ressorgiment and the Catalan collectivity of Buenos Aires (1916-1946)

DOI: http://dx.doi.org/10.12795/RiHC.2019.i12.08

Recibido: 02/04/2019

Aceptado: 04/06/2019

Publicado: $15 / 06 / 2019$

Alejandro Fernández

Universidad Nacional de Luján, Argentina

fernan625@gmail.com

ORCID D0000-0003-3294-4412 
Resumen La revista Ressorgiment alcanzó la existencia más prolongada entre todas las que crearon los emigrantes catalanes en el exterior. También fue una de las más influyentes en los ambientes del nacionalismo catalán de América Latina, hasta su cierre en 1972. En el artículo se analizan en primer lugar las razones que explican la aparición de la revista en 1916 y su rápida difusión. A continuación se presenta el elenco de sus principales colaboradores y anunciantes, en Buenos Aires y Barcelona. También se consideran las relaciones de la revista con la colectividad catalana y española de la Argentina y con los principales centros catalanistas de América, como La Habana, Montevideo y Santiago de Chile. Un examen más detallado se dedica a las opiniones de la revista respecto de Cataluña, de España y de las comunidades emigrantes. Por último, el artículo se ocupa del impacto del exilio republicano sobre Ressorgiment.

Palabras clave: Catalanismo, Ressorgiment, Buenos Aires, Prensa étnica, Emigración catalana

\begin{abstract}
The magazine Ressorgiment reached the longest existence among all those created by the Catalan emigrants abroad. It was also one of the most influential in the environments of Catalan nationalism in Latin America, until its closure in 1972. The article analyzes the reasons that explain the appearance of the magazine in 1916 and its rapid diffusion. Then there is a brief presentation of its main collaborators and advertisers, in Buenos Aires and Barcelona. The relations with the Catalan and Spanish community of Argentina and with the main Catalanist centers of America, such as Havana, Montevideo and Santiago de Chile, are also considered. A more detailed examination is devoted to the opinions of the magazine regarding Catalonia, Spain and the emigrant communities. Finally, the article deals with the impact of republican exile on Ressorgiment.
\end{abstract}

Keywords: Catalanism, Ressorgiment, Buenos Aires, Ethnic journalism, Catalan emigration

\title{
Introducción
}

Los medios de prensa creados por los inmigrantes en la Argentina han sido objeto de diferentes análisis historiográficos. Luego de los estudios pioneros de Baily (1978) y Dore (1985), se cuenta con aproximaciones a los diarios y revistas de las principales colectividades instaladas en el país, como la italiana (Bertagna, 2009; Sergi, 2012), la española (García Sebastiani, 2008) y la francesa (Oteiza, 2012). Dentro de ese panorama, la prensa catalana de Buenos Aires ha merecido hasta el momento escasos estudios específicos (Fernández, 2010), aunque ha sido considerada en otros casos, como parte de exploraciones más generales, tanto en el ámbito académico como en el institucional de la colectividad (Jensen, 2010; Lucci, 2009; Lucci, 2008; Segura-Solé i Sabaté, 2008; Castells, 2005; Castells, 1986; Manent, 1989; Irurzun 2017; Casas 2013; Rocamora 1992). Este artículo se propone contribuir a un mejor conocimiento del tema, desde la 
perspectiva de la historia de la prensa de las colectividades extranjeras y de sus relaciones con los demás ámbitos de la vida asociativa de las mismas. Para ello se emprende el abordaje de la revista Ressorgiment durante las primeras tres décadas de su existencia, un período que permite explorar el ambiente en el que se produjo su aparición y difusión, las polémicas en las que participó en el marco del desarrollo del nacionalismo catalán en la Argentina y el impacto de la guerra civil española y de la cuestión del exilio. Nuestros focos de interés se centran en el proceso de producción de la revista, en el elenco de colaboradores y anunciantes habituales y en las relaciones con la esfera del asociacionismo catalán. También se examinan los principales puntos de vista del mensuario, a través de una selección realizada entre todos los editoriales y artículos correspondientes al período.

Ressorgiment fue un genuino producto cultural y político surgido de la colectividad catalana de Buenos Aires, en una época en que ésta había pasado a ser la más importante de América, desplazando a la de La Habana. La emigración catalana a la Argentina fue persistente entre 1750 y 1950 aproximadamente, pero se verificó en pequeñas cantidades anuales, sin los saltos característicos de los movimientos de población de otras regiones de España. Esto facilitó la integración de los inmigrantes en las asociaciones que se fueron creando en la ciudad desde mediados del siglo XIX. La primera de ellas fue el Montepío de Montserrat, una sociedad de socorros mutuos que se definía como catalana y que llegó a contar con más de dos mil socios hacia 1910. La influencia del catalanismo cultural llevó en 1886 a la fundación del Centre Català, entidad que apuntaba a objetivos como la difusión del teatro, la literatura y la música de la tierra de origen. Las críticas que recibió, por el descuido de esos objetivos en favor de los meramente recreativos, llevó a la escisión de un grupo de afiliados, que junto con otros recién llegados al país fundaron en 1908 el Casal Català, cuyas iniciativas culturales asumieron desde el comienzo una impronta nacionalista y a menudo ajena a la identidad española. En ese ambiente de ferviente catalanismo, aunque manteniendo su autonomía, se produjo la aparición del medio de prensa que es objeto del presente artículo.

\section{Un mensuario de larga duración}

La revista mensual Ressorgiment, principal expresión periodística del nacionalismo catalán de la Argentina, salió a la luz en agosto de 1916 y habría de publicarse, de manera ininterrumpida, hasta 1972. La vertiente ideológica que la sustentaba fue alcanzando su efervescencia debido a la prolongación de la Primera Guerra Mundial y al paulatino colapso de los imperios multinacionales. Si bien España permaneció neutral en el conflicto, hacia el final del mismo el separatismo se hallaba definido como 
propuesta para Cataluña (Ucelay-Da Cal, 2018). Ressorgiment la sostendría en Buenos Aires, pese a que no se trataba de la primera revista de América Latina con tal orientación. En 1908 se habían iniciado las ediciones de La Nova Catalunya, de La Habana, y en 1912 las de Germanor, muy vinculada al Centre Català de Santiago de Chile. Junto con Ressorgiment, habrían de constituir la trilogía de publicaciones catalanas de América Latina que seguían el itinerario nacionalista radical. En rigor, estas revistas continuaban y profundizaban en América una tradición decimonónica de la propia Cataluña. Las primeras publicaciones catalanistas habían visto la luz en Barcelona durante el llamado Sexenio Democrático (1868-1874), en el que se amplió considerablemente la libertad de prensa. Se trataba de los semanarios satíricos, republicanos y anticlericales La Campana de Gràcia (1870) y L'Esquella de la Torratxa (1872), así como de La Gramalla (1870), portavoz de la Jove Catalunya (Anguera, 2001). La avidez por los contenidos de estas publicaciones, así como por el uso del catalán como lengua, hizo que lograran un notable éxito, sobre todo en el primer caso. Esta tendencia se extendió al Diari Català, cotidiano fundado por el político y ensayista Valentí Almirall y el primero escrito íntegramente en esa lengua (Figueres, 1999).

Ressorgiment no sólo se destacó por su inusitada duración, sino también por el rol central que desempeñó en el debate político-cultural, tanto dentro de la colectividad como con los intelectuales catalanes que visitaban el país. Sus principales contactos en el mundo asociativo de la Argentina se hallaban en el Casal Català y el Comité Llibertat de Buenos Aires, así como en algunos de los casales del interior, como el de Mendoza. Originalmente el nombre de la revista fue Resurgiment, pero ya en 1918 adquirió su grafía definitiva. A lo largo del tiempo mantuvo una notable fidelidad al formato original, de dieciséis páginas íntegramente escritas en catalán, con un editorial en la primera. La tapa se repetía en los doce números correspondientes a cada año y estaba ilustrada por un dibujo de alguno de los artistas catalanes que vivían en el país, alegórico a la emigración o al destierro, o bien a las luchas históricas de Cataluña por preservar su identidad.

La tapa correspondiente a 1918, por ejemplo, mostraba a Venus sobre las aguas del mar, con el paisaje de un pueblito de la costa catalana, al que se aproximaban algunos veleros, y al fondo las montañas. Representaba al pueblo mudo y tranquilo que dejaban atrás los emigrantes y que quizá sólo volvían a ver con los ojos de una vejez prematura. El autor era Joan Vila, un dibujante que llegó a la Argentina como prófugo del servicio militar y que, luego de unos años de sinsabores y miserias, resolvió marcharse a París, donde llegó en 1914, sobreviviendo luego en medio de muchas dificultades. La amnistía dictada por Alfonso XIII para los emigrantes prófugos le permitió retornar a Cataluña, 
donde trabajaba como dibujante en el Institut d'Estudis Catalans y para distintas editoriales, recibiendo también encargos desde la Argentina. ${ }^{1}$

En cuanto a los contenidos de la revista, se incluían de manera habitual notas sobre la geografía e historia de Cataluña, sobre su literatura, sobre las actividades de los casales del interior o de otros países latinoamericanos, sobre las visitas de catalanes al país y una sección, más ocasional, sobre normas ortográficas del catalán. Otras notas de la revista reflejaban una concepción pairalista, una evocación favorable del campo catalán y de la vida tradicional de sus comarcas, especialmente de las norteñas. A través de estas, trataba de transmitirse la imagen de un campesinado homogéneo y pacífico, como la base de la nación catalana. ${ }^{2}$ Del mismo modo, eran frecuentes los contenidos en las que se exaltaba el pasado glorioso de Cataluña, antes de la sujeción a España: los tiempos medievales y de la temprana modernidad, en los que prevalecían las instituciones y el derecho propios.

El director permanente de la revista fue Hipòlit Nadal i Mallol, nacido en Port de la Selva (Alt Empordà) y llegado al país en 1912. Pese a que era sastre de oficio, su experiencia en el periodismo barcelonés, su sobresaliente formación autodidacta y su vocación política y literaria le permitieron sobrellevar el enorme trabajo de coordinar la redacción, escribir los editoriales y algunas de las notas de cada número, además de mantener múltiples contactos con medios similares del exterior. La frecuencia mensual de Ressorgiment siempre se mantuvo, en parte por el uso de artículos publicados en rotativos catalanes, que se recibían en Buenos Aires con semanas de atraso. Dado que era un medio de opinión, más que de información, esa periodicidad no resultaba problemática, salvo cuando los acontecimientos de la península variaban con mucha rapidez, como al proclamarse la República o en determinados tramos de la guerra civil.

Entre los colaboradores habituales de la revista se encontraba la poetisa Gràcia Bassa de Llorenç, natural de Llúfriu (Baix Empordà), quien tenía a cargo la sección literaria y redactaba glosas feministas publicadas bajo seudónimo (Bacardí, 2016:28-29). Las notas de Bassa de Llorenç tendían un puente hacia los intelectuales catalanes de la Argentina que no simpatizaban con las posturas secesionistas, en tanto destacaba de ellos sus contribuciones culturales y literarias. ${ }^{3}$ Desde su domicilio en el campo enviaba sus contribuciones Enric Martí Muntaner, de Vilanova i la Geltrú (Garraf), quien fue traductor de obras de la poesía gauchesca al catalán, entre ellas el Martín Fierro. Este autor combinaba las notas literarias y políticas, presentando a las segundas con una

\footnotetext{
1 “La nostra portada”, Ressorgiment, A. III, N. 18, gener 1918, pp.282-283.

${ }^{2}$ A propósito del concepto de pairalisme, ver Llobera, 2003:86.

${ }^{3}$ Ver por ejemplo G.B.LI. [Gràcia Bassa de Llorenç], "Bécquer, poeta lírico, per J.M.Monner Sans", Ressorgiment, A. XXII, N. 247, febrer de 1937, p.4000.
} 
orientación marcadamente patriótica. ${ }^{4}$ Otro colaborador era el poeta Àngel Boixader, nacido en Vic (Osona). Ya en Cataluña se había destacado en certámenes literarios, y como dirigente del Casal Català de Buenos Aires, donde llegó a presidente, bregó por la realización de los Juegos Florales. ${ }^{5}$

Entre quienes enviaban colaboraciones desde Barcelona se destacaba Vicenç Ballester, quien en 1917 diseñó la estelada, enseña del separatismo, a partir del modelo de las banderas cubana y puertorriqueña. Ressorgiment presentaba a Ballester como "el patricio sin mancha, el batallador incansable del ideal independentista de Cataluña", el que se colocaba más allá de los partidismos. La labor de Ballester se vinculó principalmente con la ayuda a los encarcelados por razones políticas durante la Dictadura de Primo de Rivera y con la militancia en entidades civiles. Se trataba de un antiguo compañero de Nadal i Mallol, ya que había trabajado con él, antes de 1910, en el semanario Renaixement de Barcelona. ${ }^{6}$ También colaboraban desde esa ciudad periodistas como Octavi Saltor, abogado y poeta que tuvo un papel protagónico en la organización de los Juegos Florales de Barcelona en la década de 1930-39, políticos como Joan Casanovas, uno de los fundadores de Esquerra Republicana de Catalunya y presidente del Parlamento catalán en 1936, e incluso antiguos emigrantes a la Argentina, luego retornados a Barcelona, como el historiador Ramon Carreres Valls. ${ }^{7}$ Pero quizá la figura más ilustre del elenco era Antoni Rovira i Virgili, diputado de Acció Catalana Republicana y autor de una monumental Història nacional de Catalunya (Morales i Montoya y Sobrequés i Callicó, 2012:6-10), quien, según la revista, abandonó el federalismo pimargalliano para convertirse en un convencido independentista.

Ressorgiment llegó a disfrutar de una tirada de mil quinientos ejemplares, entregados mediante suscripción. Parte de ellos se enviaba hasta 1939 a la propia Cataluña, donde los familiares y amigos de Nadal i Mallol colaboraban en la distribución. ${ }^{8}$ Entre 1932 y 1936 la revista contó con un modesto y discontinuo aporte económico de la Generalitat, debido a sus frecuentes campañas a favor de la defensa de la lengua y de la educación de los catalanes de América. En los primeros años también dispuso de un elenco de aportantes, en el que figuraban una veintena de profesionales y comerciantes catalanes residentes en la ciudad, periodistas y escritores. ${ }^{9}$ Pero la principal fuente de financiación

\footnotetext{
${ }^{4}$ N.-M. [Nadal i Mallol], “Martín Fierro al català”, Martí i Muntaner, E., “L'epíleg”, Ibidem, A.XIX, N. 217, setembre 1934, p.3514 y A.XXIV, N. 273, abril 1939, p.4408, respectivamente.

5 “Àngel Boixader ha mort”, Ibidem, A. XX, N. 229, setembre 1935, pp.3692-3693.

${ }^{6}$ Nadal i Mallol, H., "Ha mort un patrici exemplar. Vicenç Ballester", Ibidem, A.XXIII, N. 266, setembre 1938, pp.4299-4300.

7 “Federalistes, no; separatistes", Ibidem, A. XIV, N. 161, desembre 1929, pp.2599.

${ }^{8}$ Entrevista con Roger Nadal, hijo de Nadal i Mallol y ex asistente administrativo de la revista, Buenos Aires, 5 de marzo 2019.

${ }^{9}$ La lista original de sostenedores fue publicada en Ressorgiment, A. I, N. 1, setembre 1916, p.23.
} 
eran los anuncios publicitarios, en su mayoría procedentes de empresas dirigidas por inmigrantes, que ofrecían bienes y servicios dirigidos a lo que podríamos denominar "mercado étnico", es decir orientados a consumos que resultaban familiares antes de emigrar. Por ejemplo, confiterías que vendían coques, panellets y pastas catalanas, introductoras de aceite de Urgell y la Ribera del Ebro, importadoras de aguas minerales y específicos de Tortosa empleados para combatir la gripe y otras afecciones, librerías que ofrecían títulos de literatura catalana o abonos a La Veu de Catalunya, importadoras de butifarras y sobrasadas, pensiones que ofrecían alojamiento en el barrio de Monserrat a un precio módico e incluyendo comidas del país de origen.

Por otro lado, también figuraban entre los anunciantes otras empresas o profesionales que no ofrecían bienes dirigidos específicamente al consumo étnico, pero que correspondían a figuras muy conocidas dentro de la colectividad o bien que evocaban en sus nombres a la tierra de origen. Entre ellos, podemos mencionar los estudios de abogados de dos ex presidentes del Casal Català, la Farmacia Catalana, el Instituto Musical Fontova -creado por uno de los fundadores de Ressorgiment-, la joyería Escasany -propiedad de uno de los integrantes más encumbrados de la colectividad-, la casa de brillantes y alhajas "El Tibidabo", la alimenticia e importadora de conservas "EI Cap Bernat", los establecimientos de calzado "La Marina" o la importadora de artículos de música, cuerdas, juguetes y útiles escolares de otro prominente dirigente del nacionalismo catalán. ${ }^{10}$

\section{Las comunidades inmigrantes}

Uno de los núcleos temáticos de Ressorgiment se encontraba, desde luego, en la situación y actividades de las diferentes comunidades catalanas de la Argentina. La cuestión no se agotaba en las noticias sobre la vida de las entidades que las representaban, sino que la revista intervenía abiertamente, expresando sus opiniones. Las reseñas sobre encuentros, festividades, recitales y conciertos celebrados en el Casal Català de Buenos Aires eran muy habituales. Generalmente redactadas en un tono laudatorio, a veces incluían, sin embargo, críticas más o menos abiertas, que podían conectar detalles relativamente menores de las mismas con las motivaciones patrióticas por las que velaba la revista. En 1933, por ejemplo, la reseña sobre los festejos del 250 aniversario del Casal informaba, en un tono neutral, sobre los dirigentes que habían hecho uso de la palabra, sobre la actuación de la Cobla Empordanesa, que había tenido a su cargo el baile de sardanas, y sobre las adhesiones enviadas por antiguos socios que

\footnotetext{
${ }^{10}$ Abundantes referencias a estas empresas y profesionales pueden verse en Blaya Alende y Giralt, 1925:81-143.
} 
habían retornado a Barcelona. Para finalizar, se señalaba que la Secció d'Art Escènic del Casal representó La llar apagada, de Ignaci Iglèsias, obra que la revista calificaba como plena de emociones y de contenido espiritual. Lo significativo es que se afirmaba que la representación no había estado a la altura necesaria, sino que sólo había sido discreta, notándose poco estudio de la letra y falta de ensayos, pese a que el elenco estaba integrado por algunos de los hombres y mujeres más conocidos como patriotas del catalanismo. $^{11}$

Cinco años después, en plena guerra civil, una larga nota enumeraba las razones que llevaron a la fundación del Casal, reconociendo que a comienzos de esa década se encontró en una difícil situación financiera, salvada mediante un empréstito interno. En 1938 debía afrontar otra crisis, ahora consistente en una pérdida del pulso patriótico y una ambigüedad de actitudes. Diferentes razones podían provocarla: la prolongación de la guerra más allá de lo que se podía vaticinar, la presión de las entidades republicanas españolas que tendían a alejar al Casal de su esencia o la incomprensión respecto de la política encarada por la Generalitat. La desaconsejable mixtura con lo español que se advertía en la península se reiteraba así en el seno de la colectividad porteña y de su institución más emblemática, augurando tiempos difíciles. ${ }^{12}$ Otros hechos, en cambio, eran para Ressorgiment más auspiciosos y permitían galvanizar su relación con el mundo asociativo, como la emotiva velada necrológica que el Casal dedicó a Manuel Carrasco Formiguera, uno de los políticos catalanes que consideraba como más ilustres, fusilado por las tropas franquistas, o la decisión del Comité Llibertat de sostener una colonia infantil en el Montseny, para niños desplazados por el avance del enemigo en Lérida y Tarragona, como ya venía haciendo el propio Casal con su colonia de niños vascos. ${ }^{13}$ Una comunidad del interior del país reiteradamente elogiada por Ressorgiment era la que se agrupaba en torno del Centre Català de Mendoza. Su núcleo catalanista fue tan relevante que, en los primeros tiempos, prácticamente contaba con una sección permanente de noticias en la revista. En un artículo de agosto de 1918, Francesc Colomer sostenía que la libertad de los pueblos generalmente había llegado cuando los Estados que los oprimían entraban en crisis, como ocurrió con los que formaban parte del Imperio turco. Es así como la crisis del Estado español podría anunciar la libertad del pueblo catalán. Los nacionalistas, en cambio, debían plantearse cooperar en la creación de un potente organismo político para luchar por ese objetivo emancipador, siguiendo ejemplos como los de Ressorgiment y del Centre Català de Mendoza. ${ }^{14}$

\footnotetext{
11 “Vint-i-cinqué aniversari del Casal Català”, Ressorgiment, A. XVIII, N. 201, abril 1933, p.3248.

12 "En el trentè aniversari del Casal Català. Historia abreujada de la seva existència”, Ibidem, A. XXIII, N. 260, març 1938, pp.4203-4204.

13 “En el Casal Català", Ibidem, A. XXIII, N. 262, maig 1938, pp.4241-4242; “Colonia infantil Comité Llibertat", Ibidem, A. XXIII, N. 268, novembre 1938, p.4335.

${ }^{14}$ Colomer, Francisc, "Per la llibertat de Catalunya", Ibidem, A. III, N. 8, agost 1918, p.413. Ver también la nota correspondiente al 30 aniversario de su fundación, en "Els catalans de Mendoza celebren un trentenari", Ibidem, A. XXIII, N. 267, octubre 1938, p.4319.
} 
La entidad también fue mencionada en la revista a propósito de una investigación judicial que comenzó en 1925, por presión de la embajada española, sobre la circulación de bonos del empréstito "Pau Claris", que Francesc Macià había puesto a la circulación desde Francia para financiar el movimiento separatista. Un juez citó a integrantes del Centre de Mendoza, que reconocieron haber adquirido bonos, pero eximieron a la institución de toda responsabilidad. La investigación judicial se reanudó tres años más tarde en Buenos Aires, a pedido del ministro de Relaciones Exteriores, Ángel Gallardo, probablemente por influencia del embajador español Ramiro de Maeztu. En esa oportunidad involucró al Casal porteño, pero el escándalo suscitado por las trabas interpuestas a la visita del propio Macià a la Argentina había sensibilizado a la prensa, que alertó sobre este nuevo hecho, destacándose las notas publicadas en Crítica y en La Vanguardia. Finalmente, todos los involucrados fueron sobreseídos. Ressorgiment atacó duramente los empeños de la embajada primorriverista y, con menos intensidad, la acción del canciller Gallardo. ${ }^{15}$

La visión positiva de la revista alcanzó igualmente a otras comunidades, como la de los catalanes de La Plata, quienes contaban con una agenda de teatro muy atractiva, que incluía comedias y dramas de autores catalanes, seguidos con gran interés por la audiencia. ${ }^{16}$ En esa suerte de "edad de oro" del catalanismo correspondiente a los años que siguieron a la Primera Guerra Mundial, también se alabó a los compatriotas de Córdoba, quienes ya contaban con un conjunto dramático, un embrión de orfeón y celebraban unas "dignas conmemoraciones de la Diada". ${ }^{17}$ El elogio adquiría mayor relieve porque, sólo unos años antes, habían sido objeto de un fuerte ataque en la revista, por su falta de organización y por el hecho de que, tanto en sus estatutos como en sus actividades, no se respiraría catalanismo ni se trataba de hablar en la propia lengua. ${ }^{18}$

Las alabanzas prodigadas a estas entidades contrastaban con las críticas que Ressorgiment dirigía a otras asociaciones, como el Montepío de Montserrat. Ya en 1922 acusó a su presidente de renegar del uso del catalán, pese a que en la mutual se lo venía empleando desde hacía medio siglo. La publicación de una hoja de propaganda había iniciado el incidente, debido a que, con el argumento de que se trataba de alcanzar al mayor número de posibles interesados, se resolvió imprimirla en castellano. El mismo argumento se usó luego para la impresión de los recibos de pago de cuotas. ${ }^{19}$ Dos años más tarde el conflicto seguía en pie, ya que Ressorgiment denunció que se pretendía

\footnotetext{
15 “Història i fi d'un procés”, Ibidem, A. XIII, N. 148, novembre 1928, pp.2391-2392.

16 "Els catalans de La Plata” y “Excursió cultural a La Plata”, Ibidem, A. VIII, N. 82, maig 1923, p.1308 y N. 83, juny 1923, pp.1320-1321, respectivamente.

${ }^{17}$ Subirachs i Cunill, LI., "Els catalans de Cordoba”, Ibidem, A. VIII, N. 83, juny 1923, pp.1323-1324. El autor de la nota era un catalán que vivía en Río IV, donde dirigía El Pueblo, principal periódico de la ciudad.

18 "Els catalans de Córdoba. Una visita al Centre Catalá”, Ibidem, A. II, N. 4, maig 1917, p.145.

19 “Per la dignitat del idioma. L'afer del Montepío de Montserrat”, Ibidem, A. VII, N. 72, juliol 1922, pp.1146-1147.
} 
convertir al Montepío en una sociedad española de socorros mutuos como cualquier otra, cuando siempre se había tratado de una institución genuinamente catalana. Una nota de Nadal i Mallol dio origen a un juicio por calumnias e injurias, en el que cada parte fue defendida por dos abogados muy conocidos de la colectividad: Carlos Malagarriga (h.) y José María Monner Sans. ${ }^{20}$ Más allá de los detalles del contencioso, por momentos algo baladíes, lo que estaba en juego era el control del Montepío, la asociación catalana que seguía reuniendo el mayor número de socios en el período de entreguerras. La revista militaba a favor de la orientación nacionalista que se trataba de extender a la mutual, lo cual concluiría en un fracaso, por lo que el interés por esta entidad fue perdiendo sustancia con el tiempo.

Otra institución que atrajo fuertes críticas por parte de la revista fue el Centre Català, por motivos que en parte se asemejaban a los del Montepío. Se lo objetaba acerbamente no solo por el uso habitual del castellano o por celebrar el Día de la Raza, sino por la similitud de sus prácticas institucionales con las de otras entidades españolas. Según describía un cronista, apenas se ingresaba en su sede, saltaba a la vista un pizarrón con anuncios de las asociaciones de hijos de Aragón, de las Castillas, de Andalucía, en fin, "de toda la España que hoy está cargada de un odio feroz contra nuestra tierra". ${ }^{21}$ La fiesta del 12 de octubre también determinó que el Orfeó Català fuera objeto de reprobación, a consecuencia de haber aceptado el convite de la Asociación Patriótica Española para participar en la misma, lo cual constituía, a su criterio, un acto humillante para Cataluña. ${ }^{22}$ En una línea similar, años más tarde se censuraría que en el Casal de Tucumán, que acababa de hacer su fiesta de inauguración, predominasen los socios no catalanes. ${ }^{23}$

Hasta el propio Josep Lleonart Nart, considerado como un ilustre patriota, sería cuestionado por la revista, dada su insistencia en lograr que se reconociera al catalán como una lengua tan española como el castellano. El comentario se produjo a raíz de una conferencia en el Ateneo Hispanoamericano, en la que disertó sobre el Tirant lo Blanc de Joan Martorell. Según Ressorgiment, no podía entenderse esa obstinación de Lleonart Nart, que no le haría bien al catalán, sino lo contrario, ya que todo lo que tendiese a marcar coincidencias con España resultaría contraproducente. ${ }^{24}$ Menos repercusión alcanzaban las noticias sobre aquellos casales que no se caracterizaban por su militancia nacionalista pero tampoco podían ser definidos como "españolistas". Entre ellos se ubicaba el Centre Català de Rosario, al cual se le dedicó por primera vez una nota específica en junio de 1934. En ella se destacaba la labor cultural que venía desarrollando desde su fundación en 1902: escuela orfeónica, clases de escultura, grupo

\footnotetext{
20 “L'afer del Montepío de Montserrat", Ibidem, A. X, N. 102, gener 1925, pp.1657-1659.

${ }^{21}$ D’Arlés, Joan: “D’un Centre que es titula català”, Ibidem, A. IV, N. 34, maig 1919, p.542.

22 “Actitud antipatriótica”, Ibidem, A. VII, N. 77, novembre 1922, pp.1208-1209.

23 “Els catalans de Tucumán”, Ibidem, A. XII, N. 127, febrer 1927, pp.2064.

24 “Petit escoli a una conferència”, Ressorgiment, A. VII, N. 78, decembre 1922, p.1227.
} 
teatral, biblioteca. Se agregaba que este Centre había actuado como anfitrión de huéspedes de honor del calibre de Francesc Macià, Eugeni d'Ors, August Pi Sunyer, Margarita Xirgu y Santiago Rusiñol. ${ }^{25}$

Las convocatorias de la revista quedaron a veces en el olvido, como ocurrió con la exhortación para que los catalanes residentes en América renunciaran a la ciudadanía española y adoptaran la de los países receptores. A comienzos de 1923, Nadal i Mallol esbozó la idea, planteando que, puesto que el pueblo catalán no podía legalmente disponer de la ciudadanía de la patria de origen, tanto daba adoptar la de cualquier otro país que no fuese España. Por ende, lo más conveniente era optar por la de las repúblicas anfitrionas. ${ }^{26}$ Luego del golpe de Primo de Rivera, retornó con más enjundia sobre esa propuesta, señalando que, si sus compatriotas decidieran convertirse en ciudadanos argentinos, ello no implicaría ningún menoscabo de su condición de catalanes. Incluso añadió una forma concreta en que podría llegar a realizarse, mediante una reunión en cada pueblo o ciudad en donde existiera una colonia catalana, a fin de adoptar en bloque la ciudadanía argentina. ${ }^{27}$

Para concluir, cabría mencionar que en numerosas oportunidades Ressorgiment dedicó sus columnas a destacar las acciones o planteamientos de la dirigencia argentina, o bien de los propios inmigrantes catalanes, que reforzaran los nexos bilaterales o mostraran el éxito alcanzado en la sociedad receptora. Entre las primeras, puede recordarse su aquiescencia a la iniciativa de Leopoldo Lugones, entonces director de la Biblioteca Nacional de Maestros, para que en ella se reunieran ejemplares de literatura escrita en catalán, teniendo en cuenta que los libros que allí existían de autores de ese origen como Pi Margall- eran antiguos y estaban publicados en castellano. ${ }^{28}$ Sobre lo segundo, un ejemplo ilustrativo es el de los elogios a Joaquín Coca, un artesano nacido en Barcelona y militante del Partido Socialista argentino, cuando fue elegido diputado nacional. La nota correspondiente recordaba las actividades sindicales en las que había participado desde su juventud, las persecuciones que soportó, su formación intelectual completada luego de las horas dedicadas al trabajo manual y su llegada al país en 1911, en busca de paz y trabajo. También mencionaba que en 1914 se había afiliado al socialismo, que había participado en diversos congresos y pertenecido a la redacción de La Vanguardia. Pese a que Coca no mantenía una vinculación directa con el catalanismo de la Argentina, Ressorgiment destacaba en su caso las posibilidades de superación al alcance de los emigrantes una vez que escapaban a la influencia del Estado opresor. ${ }^{29}$

\footnotetext{
25 “Institucions catalanes a l'Argentina”, Ibidem, A. XIX, N. 215, juny 1934, p.3473.

${ }^{26}$ Nadal i Mallol, H., "La ciutadania adoptiva”, Ibidem, A. VIII, N. 79, gener 1923, p.1239.

${ }^{27}$ Nadal i Mallol, H., "Fem-nos ciutadans argentins", Ibidem, A. VIII, N. 88, octubre 1923, p.1385.

28 “Una secció catalana a la Biblioteca Nacional de Maestros”, Ibidem, A. VIII, N. 81, abril 1923, p.1283.

29 "Un català, diputat por Buenos Aires", Ibidem, A. IX, N. 93, abril 1924, p.1482.
} 


\section{Núcleos del debate catalanista}

Las discusiones suscitadas por Ressorgiment respecto del catalanismo no se agotaban en la esfera asociativa de la Argentina. Incluso políticos nacionalistas recibieron duras críticas cuando su actitud no alcanzaba la intransigencia. En agosto de 1919, el fisiólogo y diputado August Pi Sunyer visitó Buenos Aires, y su discurso ante los catalanes fue comentado con severidad. Sostenía la revista que esperaba otra cosa de un político que dictaba sus clases universitarias en catalán -práctica que no era habitual en la época- y que fue uno de los redactores de las bases elevadas al gobierno para la autonomía de Cataluña. Ahora parecía que él se conformaba con lo ya obtenido y, a lo sumo, reclamaba la autonomía, cuando debía tratarse de obtener la soberanía integral. ${ }^{30} \mathrm{Pi}$ Sunyer, afectado por la nota, solicitó una reunión con las instituciones catalanas, en la que reclamó el derecho a réplica. ${ }^{31}$ En la misma, ratificó su no adhesión al separatismo y criticó los pequeños cenáculos, a veces enfrentados, que había observado en Argentina y Uruguay. Atribuía a ese factor la escasa adhesión a la Associació Protectora de l'Ensenyança Catalana, una empresa cultural que debía convocar a todos. En su respuesta final, Nadal i Mallol sostuvo que entre los catalanes del Río de la Plata no había la más leve disparidad ideológica, sino sólo diferencias en la manera de entender la obra colectiva. A su criterio, la política estaba marginada de tales círculos, puesto que el nacionalismo no era propiamente política sino patriotismo. ${ }^{32}$

La curiosa noción expuesta en esa nota, según la cual al militar por la soberanía nacional de Cataluña no se estaba haciendo política, estaba lejos de constituir una actitud ocasional, ya que la revista hacía profesión de fe de su independencia respecto de los partidos, amparándose en un patriotismo catalanista equidistante de todos ellos. Desde sus comienzos sostuvo la idea de que ese patriotismo debía situarse al margen de la política: "Ya lo hemos dicho una infinidad de veces: el nacionalismo no es política". ${ }^{33}$ Esto contribuye a explicar algunas de sus predilecciones, como la que manifestara respecto de la figura de Vicenç Ballester, un patriota abnegado que se había concentrado en acciones dignas del aplauso unánime, como la de diseñar la bandera independentista $o$ la de confortar material y espiritualmente a los compañeros que sufrían penas de prisión. Es probable que, detrás de dicha actitud, se ocultase un cierto desdén por la lucha política concreta o por las vicisitudes de su práctica. Más allá de esa conjetura, pocas dudas caben de que Ressorgiment luego vulneraba en los hechos su profesión de $\mathrm{fe}$, ya que a menudo expresaba su preferencia por determinados grupos o partidos

\footnotetext{
30 "El discurs del doctor Pi i Suñer", Ibidem, A. IV, N. 38, setembre 1919, pp.595-596.

31 “El Dr. Pi i Suñer y Ressorgiment”, Ibidem, A. IV, N. 39, octubre 1919, p.611.

${ }^{32} \mathrm{Pi}$ i Suñer, August, “Ressorgiment i jo", y Nadal i Mallol, Hipòlit, “Contrarèplica final”, Ibidem, A. V, N. 44, març 1920, pp.691-694.

33 “Associació Nacional Catalana de les Amèriques”, Ibidem, A. II, N. 12, decembre 1917, p.266 (traducción propia). La impresión fue ratificada en la entrevista con Roger Nadal, op.cit., quien sostuvo que su padre era muy nacionalista pero "nunca se metió en política".
} 
políticos del país de origen en desmedro de otros, aun cuando todos ellos se proclamaran catalanistas.

Argumentos similares a los empleados con Pi Sunyer, aunque más contundentes, fueron los de de Nadal i Mallol en su polémica con el corresponsal que la revista La Publicitat, de Barcelona, destacó en Santiago de Chile. Las relaciones de Ressorgiment con esta publicación eran bastante estrechas, incluyendo la reproducción de artículos, como los redactados por Rovira i Virgili. En 1933, sin embargo, dicho corresponsal sostuvo que en los casales americanos reinaba la apatía, lo cual mereció una firme respuesta. Nadal i Mallol admitió que la descripción era certera en muchos lugares, porque los compatriotas que se afiliaban a los casales carecían de información sobre lo que ocurría en Cataluña o no se caracterizaban por su compromiso con la causa de la patria. Pero aseguraba que parte de la responsabilidad le cabía a los nuevos integrantes de la Generalitat recuperada, ya que ellos no le habían reconocido a los catalanes de América el lugar que merecían luego de haber luchado tanto por la patria y, por lo tanto, no apoyaban a los casales en la medida que habría cabido esperar. Yendo más al centro de lo afirmado por el corresponsal, respondía que éste no debía conocer el de Buenos Aires, cuyas iniciativas y actividades lo apartaban por completo de la apatía descripta. ${ }^{34}$

Fuera del ámbito de la colectividad, uno de los periodistas con los que Nadal i Mallol se trenzó en más de una polémica fue Mario Aguilar, de El Día Gráfico, de Madrid. En enero de 1921, Aguilar cuestionó a las revistas del nacionalismo catalán americano, considerando que todas ellas podrían provenir de la misma imprenta, aunque se publicaran en Santiago de Chile o en La Habana:

Aparecen los versos floralescos, se reproducen los discursos del señor Cambó, se habla de los festejos de la colonia y publican cada dos meses el retrato de Guimerá (...) A veces, aparecen las fotografías de los actos de estos filibusteros de la Habana o de Mendoza. Entonces los vemos, en un gran salón, cuando ha llegado el momento de la sardana, o bien bajo unos árboles, en el descanso de la excursión, agrupados fraternalmente con el pensamiento en Cataluña. Uno sostiene una bandera catalana, y la extiende otro, agarrándola de un cabo, para hacerla más visible. Algunos llevan barretinas, a la ampurdanesa. Son todos jóvenes, menos algún cincuentón al que debieron convencer, y que debe haber comenzado a escribir en catalán a los cuarenta y cinco. ${ }^{35}$

A lo largo del tiempo, la revista defendió a las instituciones políticas catalanas, cuya existencia fue efímera. La Mancomunitat de Catalunya, surgida en 1914, fue elogiada por su labor de recuperación del patrimonio cultural y jurídico del país, así como por sus intentos de recuperar la paz social durante la etapa de agitación de 1919-20. Respecto

\footnotetext{
${ }^{34}$ Nadal i Mallol, Hipòlit, “Un corresponsal mal informat”, Ibidem, A. XVIII, N. 208, novembre 1933, p.3481.

${ }^{35}$ Citado en "Marius Aguilar i nosaltres", Ibidem, A. VI, N. 54, gener 1921, p.864.
} 
de este problema, Ressorgiment sostenía que los conflictos sindicales actuaban como una distracción, fomentada por los gobiernos madrileños, de la lucha por la autonomía o la independencia, si bien admitía en esa coyuntura que la burguesía debía otorgar concesiones a los trabajadores, teniendo en cuenta las ganancias que había acumulado durante la guerra. ${ }^{36}$ Cuando se produjo el golpe de Estado de Primo de Rivera, argumentó que sus causas no debían buscarse en la situación militar que España enfrentaba en Marruecos, sino en la de Cataluña, cuyas ambiciones de libertad los nacionalistas españoles querían sofocar a todo trance. ${ }^{37}$ Desde comienzos de 1924 , el referente político fue Francesc Macià, a quien ponderaba por su lucha en favor de los ideales de independencia, ahora desde el exilio en Francia. ${ }^{38}$

\section{La República y la guerra}

La militancia nacionalista de Ressorgiment siguió siendo muy intensa durante la etapa de la república. En mayo de 1931 dedicó una amplia nota al banquete de adhesión al gobierno provisional de Cataluña, celebrado en Buenos Aires, al cual asistieron más de trecientos comensales. ${ }^{39}$ Sin embargo, una decepción con la nueva realidad política surgió de la aprobación del estatuto de autonomía en 1932, al considerarlo restrictivo e insuficiente en varios aspectos vinculados a la soberanía. Entre ellas, la cuestión clave de la oficialidad del idioma. Es así que censuró la disposición constitucional por la que todos los españoles tendrían la obligación de conocer el castellano. Ressorgiment sostenía que, si esa normativa no había sido impuesta ni siquiera por los gobiernos absolutistas del siglo XIX y, en cambio, la República era la que lo sancionaba, se debía al propósito de cerrar el camino a cualquier reconocimiento de la co-oficialidad del catalán. ${ }^{40}$ Otro ámbito respecto del cual lamentaba las escasas facultades del gobierno autónomo era el de la política inmigratoria, ya que la Generalitat estaría inerme frente a la población expulsada de las regiones meridionales de España por la crisis económica. ${ }^{41}$

En cuanto a las colectividades radicadas en América, Ressorgiment lamentaba la insuficiente atención que se les prestaba, no obstante el apoyo que habían brindado

\footnotetext{
36 “La impostura”, Ibidem, A. V, N. 42, gener 1920, p.659; “El joc del sindicalisme”, N. 44, març 1920, p.691; "El president de Catalunya traça el camí, A. V, N. 47, juny 1920, p.739.

37 "La dictadura militar a Espanya", Ibidem, A. VIII, N. 87, octubre 1923, pp.1379-1380.

38 “Francesc Macià", Ibidem, A. IX, N. 91, febrer 1924, pp.1444.

39 “Acte d'adhesió al govern provisional de Catalunya”, Ibidem, A. XVI, N. 178, maig 1931, pp.2878-2879.

40 “La marca de l'esclau, encara”, Ibidem, A. XVIII, N. 199, febrer 1933, p.3207.

41 “Un problema d'immigració”, Ibidem, A. XVIII, N. 201, abril 1933, pp.3240-3241.
} 
para la obtención de la autonomía. Un ejemplo de ello lo hallaba en la inacción de la Generalitat frente al proyecto de crear una biblioteca catalana en la Facultad de Filosofía y Letras de la Universidad de Buenos Aires. Pese a que Macià se había interesado en esta iniciativa, luego de su muerte había caído en el olvido. ${ }^{42}$ La presión en favor de un mayor apoyo del gobierno autónomo se incrementó debido a la presencia de retornados desde la Argentina y otros países latinoamericanos, que conservaban unos vínculos estrechos con las comunidades emigrantes. Un grupo de ellos, representativo del nacionalismo radical, creó en Barcelona la Associació Catalans d'Amèrica, que, a través de conferencias y otras actividades, trató de promover la cooperación de la Generalitat con esas colectividades. ${ }^{43}$ Las iniciativas de este grupo fueron mencionadas varias veces por la revista hasta mediados de $1936 .{ }^{44}$

Por su parte, los políticos de la derecha catalana eran caracterizados en Ressorgiment como derrotistas y antinacionales, debido a su tendencia a colaborar con los gobiernos españoles o a solicitar la intervención del Estado para abolir decisiones soberanas del propio Parlamento catalán. No obstante, tampoco los dirigentes de los partidos de izquierda resultaban indemnes, ya que a menudo los acusaba de realizar genuflexiones ante Azaña y sus ministros, dejando de lado los reclamos de una autonomía más amplia para Cataluña. Las elecciones de febrero de 1936 dieron ocasión para una moderada celebración y para la exhortación a los representantes a los que les tocaba gobernar a que no actuasen por intereses partidistas, sino conformando un frente único ante el enemigo común. ${ }^{45}$ Esta propuesta de unidad de los patriotas catalanes reaparecería constantemente en los meses siguientes, no solamente como llamado a la resistencia frente a los militares sublevados, sino también contra los revolucionarios y terroristas que actuaban en la propia Barcelona y no estaban dispuestos a la obediencia a la autoridad legítima representada por la Generalitat. ${ }^{46}$

Con la guerra iniciada, la revista celebró que Cataluña sostuviese el esfuerzo republicano y enviase tropas a Aragón. Contra las afirmaciones de que sería mejor reservarlas para el propio territorio, señalaba que el eterno enemigo de los catalanes era el ejército español, por lo que se trataba de enfrentarlo afuera, para no tener que padecerlo nuevamente. También reconocía la existencia de graves excesos del lado propio, lo cual generaba en mucha gente el temor al triunfo del comunismo. Pero hallaba sus causas

\footnotetext{
42 “A propòsit d'una iniciativa”, Ibidem, A. XX, N. 227, juny 1935, p.3643.

${ }^{43}$ Solà i Vilanova, C., “A propòsit d'una conferencia”, Ibidem, A. XIX, N. 216, juliol 1934, p.3481.

44 "El nostre patriotisme" y "Iniciativa de I'Associació Catalans d'Amèrica, de Barcelona”, Ibidem, A. XXI, N. 234, gener 1936, p.3755-3756; A. XXI, N. 239, juny 1936, p.3835, respectivamente.

45 "L'Estatut, recobrat", Ibidem, A. XXI, N. 236, març 1936, p.3787, y “Consideracions de l'hora”, A. XXI, N. 237, abril 1936, p.3803.

46 "Cap a la normalització de la vida catalana” y Martí i Muntaner, E., “Orientacions perilloses”, Ibidem, A. XXII, N. 247, febrer 1937, pp.3991-3992, y A. XXIII, N. 260, març 1938, pp.4199-4200, respectivamente.
} 
en la insuficiente catalanización de las masas, por lo que dichas acciones no resultaban representativas de la nacionalidad. ${ }^{47}$ La lucha emprendida, tal como la observaba Ressorgiment, acarrearía consecuencias extremas: o Cataluña caía bajo una dictadura fascista o hasta era posible que lograse su independencia. Por lo tanto, aconsejaba no temer a la revolución, dado que se luchaba por algo más que ganar la guerra y se lo hacía bajo la dirección de un gobierno propio. ${ }^{48}$

Las certezas se erosionaron a medida que el conflicto fue vaciando de contenido a algunas de las instituciones que tanto esfuerzo había costado conseguir, como el Parlamento catalán, que no había vuelto a reunirse desde el alzamiento. ${ }^{49}$ También se deploraría que la Generalitat no pudiera contar con los suficientes medios como para controlar a los elementos terroristas, que seguían gozando de impunidad. Mientras el pueblo se lanzaba a una lucha desesperada para contener a los militares sublevados, dichos elementos se dedicaban a la destrucción, la quema de iglesias y el saqueo. ${ }^{50}$ Las crecientes dificultades a enfrentar hicieron que, desde mediados de 1937, los llamados a la colaboración de los emigrantes catalanes se volvieran permanentes, así como la información sobre entregas de las ayudas enviadas por el Casal de Buenos Aires. ${ }^{51}$

Cuando la situación se tornó aún más dramática, Sara Llorens, argentina hija de catalanes y esposa del político Manuel Serra Moret, escribió una nota en la que, con una perspectiva abarcadora, destacaba la magnanimidad de Iberia y calificaba al conflicto no como una guerra de invasión e independencia, sino como una confrontación secular entre dos mundos. Frente a la presencia de la muerte y de los verdugos, llamaba a los pacifistas a perseverar en la lucha contra el fascismo, sin importar las penurias a soportar en la retaguardia, ya que lo único que cabía era alimentar y abrigar a los soldados del frente. ${ }^{52}$ Ese eje confrontativo fascismo-antifascismo, alternaba con el más tradicional de España-Cataluña, entendidas como opresora y oprimida. En esta perspectiva, el hecho de que Cataluña estuviera combatiendo junto a España por la defensa de sus instituciones frente a los militares alzados no significaba que hubiese olvidado la secular sujeción a la que la segunda la seguía sometiendo. ${ }^{53}$

\footnotetext{
${ }^{47}$ Casanova, J., "Sota l'interrogant del temps nou", Ibidem, A. XXI, N. 241, agost 1936, p.3876; Castelló, LI., "Del moment" y Nadal i Mallol, Hipòlit, "El nostre deure", N. 242, setembre 1936, pp.3914-3916; Rovira i Virgili, A., "El Kremlin de Barcelona”, A. XXII, N. 248, març 1937, p.4013.

${ }^{48}$ Nadal i Mallol, H., “Aspectes de la Revolució”, Ibidem, A. XXI, N. 244, novembre 1936, p.3950.

49 “I el Parlament de Catalunya?", Ibidem, A. XXII, N. 246, gener 1937, p.3975.

50 “Dos fets cabdals", Ibidem, A. XXII, N. 256, novembre 1937, p.4135.

51 “Crida urgent”, Ibidem, A. XXII, N. 255, octubre 1937, p.4119; "Valoració de la Catalunya d'Amèrica”, A. XXIII, N. 258, gener 1938, pp.4172-4173.

52 “L'ajut al front de guerra”, Ibidem, A. XXIII, N. 265, agosto 1938, pp.4280-4281.

53 “Regionalisme, encara?”, en Ibidem, A. XXIII, N. 259, febrer de 1938, pp.4189.
} 
Una línea argumental similar aparece en las notas en que, estando ya el territorio propio en manos franquistas, convocaban a los emigrantes a la única tarea importante de allí en más, la de luchar por las libertades de Cataluña. En una de ellas se sostenía que, mientras duró la guerra, la Generalitat, obligada por las circunstancias, debió seguir la línea equivocada de la colaboración con el Estado opresor, pero había llegado la hora de abandonarla para concentrarse en los objetivos de siempre, esto es en la recuperación de una catalanidad estricta. Asimismo, argüía que en la guerra no había existido la reciprocidad, ya que Cataluña cumplió todas las leyes de la República e hizo el máximo esfuerzo, pero a la hora de tener que defender su territorio, se vio condenada a una completa soledad. De manera un tanto curiosa, teniendo en cuenta la hecatombe del bando republicano y la sangrienta represión que ya se abatía sobre Cataluña, la revista esbozaba proyectos para el futuro, con opciones que parecían al alcance de la mano. ${ }^{54}$ Es probable que esa evidente desconexión entre planes y realidades pueda explicarse porque las fuentes de información de lo que ocurría en el país de origen ya eran muy escasas, las noticias llegaban con cuentagotas y resultaba casi imposible chequear su veracidad. La incertidumbre se añadía así al dolor por una derrota que no se columbró por completo hasta la misma víspera de su concreción.

Todavía más enfática era la reafirmación de que la cuestión clave seguía siendo la soberanía de Cataluña. Según declaraba Nadal i Mallol en la introducción a una carta abierta enviada por Joan Casanovas desde París, esas convicciones le habían costado muchos sinsabores dentro de la colectividad, muchas censuras y ataques, pero siempre se habían demostrado acertadas: antes de la aprobación del estatuto de autonomía, luego de que éste entrara en vigor y, más aún, durante la guerra. Cataluña, en suma, debía concentrarse en la lucha por su propia soberanía. Ni monarquía ni república: Cataluña. No la Cataluña de Cambó ni la del estatuto de 1932, sino la de Macià y el Estat Català. Como corolario, Casanovas, que había presidido el Consell Executiu del gobierno de Companys, reconocía en su carta, fechada en abril de 1939, que mantuvo una posición de colaboración con España hasta el alzamiento, pero que la guerra le había hecho ver las cosas con otra perspectiva. Llegaba así a una conclusión, que acaso sintetizaba como ninguna otra lo que la propia revista postulaba en ese momento: "Ni Negrín, ni Franco. Ni puño cerrado ni palma extendida. (...) Cataluña soberana: ni más ni menos". ${ }^{55}$

\footnotetext{
54 “Orientacions”, Ibidem, A. XXIV, N. 272, març 1939, p.4391; “Unitat nacional”, Ibidem, A. XXIV, N. 276, juliol 1939, p.4455.

55 “L’única solució", Ibidem, A. XXIV, N. 275, juny 1939, pp.4447-4448 (traducción propia).
} 


\section{Ressorgiment y el exilio}

A partir de 1939, Ressorgiment mantuvo los contactos que poseía antes de la guerra con publicaciones similares de otros países latinoamericanos y agregó otros nuevos, como el de los Quaderns de l'Exili, que vieron la luz en Coyoacán (México) entre 1943 y 1947 (Pla Brugat, 1999: 317). Sin embargo, la incorporación de los exiliados a la redacción fue poco significativa: tan solo Pere Mas i Perera colaboró regularmente durante muchos años, principalmente con artículos sobre historia de Cataluña y de sus instituciones. Se trataba de un escritor y militante de Acció Catalana Republicana que había ocupado cargos de segunda importancia en el gobierno de la Generalitat, y que a poco de concluir la guerra se exilió en Buenos Aires, donde moriría en 1977. Fue uno de los impulsores de los Juegos Florales de 1941, primeros de la época del exilio. Otros desterrados en la capital argentina escribieron ocasionalmente en Ressorgiment, pero sólo Mas i Perera lo hizo con asiduidad. La revista siguió esencialmente a cargo de Nadal i Mallol, junto con tres o cuatro de sus antiguos colaboradores.

En cambio, eran frecuentes las notas de los exiliados catalanes en otros países, como Francia, Inglaterra o México, sobre todo de aquellos que se orientaban a las posiciones más contundentes dentro del nacionalismo. Un ejemplo es el periodista y político Marcel·lí Perelló, ex secretario del partido Estat Català y jefe de su agrupación paramilitar Escamots. En la guerra civil, Perelló dirigió el Diari de Barcelona, confiscado por la Generalitat, y, a partir de 1942, residió en México, desde donde enviaba contribuciones a la revista porteña. Al mismo grupo pertenecía Josep Maria Murià, poeta y narrador que había militado en Estat Català y actuado como funcionario de la Generalitat durante la guerra civil. También se exilió en 1942 en México, donde sería uno de los animadores del Centre Català de Guadalajara. En la experiencia del Diari de Barcelona, junto con Perelló, tomó parte como redactor Manuel Cruells, otro de los futuros colaboradores de Ressorgiment. Por su parte, el antropólogo Josep Maria Batista i Roca, participante en los grupos paramilitares del nacionalismo radical durante los años veinte, se exilió en Inglaterra luego de la guerra, fue profesor en la Universidad de Cambridge y secretario del Consell Nacional de Catalunya, dirigido por Carles Pi Sunyer. La mayor parte de las notas enviadas por Batista i Roca corresponden a esa etapa de exilio londinense. Entre los catalanes de América, uno de los nacionalistas más destacados que colaboró ocasionalmente con la revista fue Joaquim Casamitjana, presidente del Centre Català de La Habana y uno de los editores de la radicalizada revista iFora Grillons!

El impacto del exilio debe evaluarse sin embargo en otro plano, y es el de su frecuencia como cuestión central para Ressorgiment. Los llamados a la unidad de los catalanes exiliados fueron permanentes, así como su apoyo a los organismos que trataban de llevar a la práctica ese propósito, como el mencionado Consell Nacional con sede en 
Londres. ${ }^{56}$ Pocos años más tarde deploraba que esa creación, lograda bajo tan buenos auspicios como el de la presidencia de Pi Sunyer y la adhesión de una extensa red de asociaciones catalanas de América, no hubiese logrado resultados concretos y se asistiese en cambio a una fragmentación de las instituciones nacionales. Los vascos, a su criterio, acababan de dar una valiosa lección a los catalanes con la reunión de su gobierno en Nueva York, presidido por el lehendakari Aguirre y apoyado por todos, desde los católicos a los comunistas, pasando por las organizaciones sindicales. ${ }^{57}$ Ressorgiment enfrentó los sucesivos retrocesos en ese proceso de unidad, hasta la formación del gobierno Tarradellas en 1954, con la repetida prédica de la cohesión nacional en el extranjero. ${ }^{58}$

La apelación a la unidad de los catalanes también se refería a las instituciones de Buenos Aires, a fin de defender la identidad propia. Es así como, al producirse la fusión del Centre Català y el Casal Català en 1940-41, dejó de lado las duras críticas dirigidas a la primera entidad para ponderar el ejemplo patriótico que ese acto representaba. ${ }^{59}$ Además, revaloró las iniciativas culturales sobre las que previamente era más bien pesimista, como los Juegos Florales, señalando que esa fiesta tradicional se había convertido, por imperio de las circunstancias, en una manifestación de afirmación nacional por parte de los exiliados y emigrantes. ${ }^{60}$ También fue dando cabida en sus páginas a colaboraciones que se apartaban de su posición separatista, siempre y cuando se tratara de expresiones del nacionalismo catalán. Un ejemplo puede hallarse en la reproducción de la proclama lanzada por Carles Pi Sunyer, desde el Consell Nacional de Catalunya, instalado en Londres. ${ }^{61}$

Por su parte, la sintonía de la revista con los organismos republicanos españoles del exilio atravesó marcados vaivenes. Luego de un punto muy elevado en ocasión de las manifestaciones de solidaridad de aquellos ante el fusilamiento del presidente Companys, tendieron paulatinamente a debilitarse frente al recordatorio de los sacrificios realizados por Cataluña para defender las instituciones republicanas y del hecho de que, durante la guerra, pudiendo haberse independizado, aquella había desistido de hacerlo. ${ }^{62}$ En noviembre de 1944, sin embargo, Ressorgiment se hacía eco

\footnotetext{
56 "Dos fets importants", Ibidem, A. XXVI, N. 299, juny 1941, p.4823; Mas i Perera, P., "Missió histórica dels catalans emigrats", Ibidem, A. XXVIII, N. 325, agost 1943, pp.5289-5290.

57 “L'exemple dels bascos", Ibidem, A. XXX, N. 345, abril 1945, pp.5607-5608.

58 "Pel bon camí", Ibidem, A. XXXIII, N. 382, maig 1948, p.6199; "Un document important”, A. XXXIV, N. 401, desembre 1949, p.6479; “Inercia col'lectiva”, A. XXXVI, N. 414, gener 1951, p.6703.

59 “Crida al patriotisme”, Ibidem, A. XXV, N. 289, agost 1940, p.4663; “Mentre la pàtria agonitza”, A. XXV, N. 290, setembre 1940, p.4679.

${ }^{60}$ Ferrer, M., "El valor polític dels Jocs Florals de l'exili", Ibidem, A. XXXVI, N. 424, setembre 1951, pp.69526953.

${ }^{61}$ Pi Sunyer, C., "La unitat dels catalans”, Ibidem, A. XXVI, N. 296, març 1941, pp.4784-4785.

62 “L'única esperança”, Ibidem, A. XXVII, N. 312, juliol 1942, p.5075.
} 
del documento elaborado por el Consell Nacional, en el que se sostenía que la causa de las libertades catalanas iba inexorablemente unida a la de la democracia española. Por ello apoyaba el propósito de extender la mano a los defensores de esta última, en una lucha que debía ser común. ${ }^{63}$ La apelación a los valores propios de la Segunda República reapareció en las ocasiones en que la derrota afectaba al exilio catalán y al español en su conjunto, como cuando el régimen de Franco logró la admisión en la UNESCO y luego en la ONU. ${ }^{64}$

\section{Conclusiones}

La revista Ressorgiment fue el portavoz más decidido y persistente del nacionalismo catalán en Buenos Aires. Su publicación se inició de manera casi simultánea con la irrupción de las posturas separatistas en la propia Cataluña, con la cual estuvo ligada por vínculos muy fluidos hasta el final de la guerra civil española. Los principales acontecimientos políticos de la patria de origen, como la supresión de la Mancomunitat, la proclamación de la República, la aprobación del estatuto de autonomía, el fracaso del alzamiento franquista en Barcelona, las vicisitudes del conflicto bélico o el fusilamiento del presidente Companys, influyeron poderosamente sobre las opiniones del mensuario. Pero también tuvo su importancia la dinámica de la propia colectividad residente en la Argentina, puesto que, mientras que algunas de sus instituciones tenían una gran afinidad con Ressorgiment, que las presentaba como ejemplos de patriotismo y de genuina labor cultural catalanista, en otros casos las relaciones estuvieron signadas por la crítica y el enfrentamiento. Las posiciones radicales que expresaba la revista no fueron hegemónicas entre los catalanes de Buenos Aires y sería difícil incluso sostener que en algún momento llegaran a ser mayoritarias, con la posible excepción de un breve período a partir de la derrota de 1939. Sin embargo, su difusión y prestigio eran apreciables, no solo en la ciudad, sino en los restantes lugares del país o de América Latina donde existían densas comunidades catalanas. Esto llevó a que varios de los más destacados exiliados de la posguerra publicaran ocasionalmente notas en sus páginas, aunque no se integraron en el elenco de redacción.

A lo largo de las tres décadas consideradas en el presente artículo, se advierte con claridad en la práctica cotidiana de la revista la presencia de los dos segmentos dirigenciales que más a menudo han sido identificados entre las colectividades inmigrantes. Por una parte, los periodistas, escritores y literatos que sostenían la

\footnotetext{
63 “La nova solución”, Ibidem, A. XXIX, N. 340, novembre 1944, pp.5527-5528; “Davant l'Assemblea de les Nacions Unides", Ibidem, A. XXXII, N. 374, setembre 1947, p.6071.

64 “Süicidi de la Unesco", Ibidem, A. XXXVII, desembre 1952, p.7051.
} 
afirmación étnica en el marco de una sociedad en la que las presiones hacia la integración eran considerables y en la que los intentos de construcción de la identidad catalana debían enfrentar la competencia proveniente de un hispanismo sólidamente implantado en el ámbito de las asociaciones y en el de la prensa. El director Nadal i Mallol y sus colaboradores más habituales expresaban los puntos de vista del nacionalismo catalán a través de los editoriales y artículos de opinión incluidos en Ressorgiment, pero también cuando actuaban como referentes de la colectividad en las conmemoraciones públicas y eventos culturales. Por la otra, en una posición quizá menos visible, los comerciantes y empresarios inmigrantes que publicitaban en las páginas de la revista una serie de bienes y servicios que, a menudo, iban dirigidos de preferencia a un público constituido por sus propios paisanos y compatriotas. Los integrantes de este segundo grupo solían formar parte de las juntas directivas de las asociaciones catalanas de la ciudad o bien colaboraban con ellas mediante contribuciones pecuniarias o de otro tipo. Además, en el caso de los más prósperos, podían ser presentados como ejemplos de un encumbramiento que todo lo debía a la laboriosidad y la capacidad emprendedora de los catalanes fuera de España.

\section{Bibliografía citada}

ANGUERA, P. (2001), “El nacionalismo catalán desde sus orígenes a 1930”, en GUEREÑA, J.L. (ed.), Les nationalismes dans l'Espagne contemporaine. Idéologies, mouvements, symboles, Paris, Editions du Temps, pp.117-146.

BACARDÍ, M. (2016), Gràcia Bassa, poeta, periodista i traductora, Palafrugell, Ajuntament de Palafrugell.

BAILY, S. (1978), "The Role of Two Newspapers and the Assimilation of Italians in Buenos Aires and San Paulo, 1898-1913", International Migration Review, Vol 12, Issue 3, pp.321-340.

BERTAGNA, F. (2009), La stampa italiana in Argentina, Roma, Donzelli Editore.

BLAYA ALENDE, J.-GIRALT, J. (1925), El progreso catalán en América, Tomo II, Argentina y Paraguay, Santiago de Chile, Blaya Alende Editores.

CASAS, S. (2013), Militancia republicana, identidad nacional y sociabilidad comunitaria de los catalanes en la Argentina (1920-1945), Tesis de doctorado, Universidad Nacional de la Plata, Facultad de Humanidades y Ciencias de la Educación.

CASTELLS, V. (2005), Nacionalisme català à l'exili, Barcelona, Rafael Dalmau editor. 
- (1986), Catalans d’Amèrica per la independència, Barcelona, Pòrtic.

DORE, G. (1985), "Un periódico italiano en Buenos Aires (1911-1913)”, en DEVOTO, F.ROSOLI, G. (comps.), La inmigración italiana en Argentina, Buenos Aires, Biblos, pp.127-140.

FERNÁNDEZ, A. (2010), "La revista Catalunya de Buenos Aires, el exilio y la colectividad inmigrada (1927-1964)", en Estudios Migratorios Latinoamericanos, A. 24, N. 69, julio-diciembre, pp.389-412.

FIGUERES, J.M. (1999), El primer diari en Ilengua catalana. Diari Català, 1879-1881, Barcelona, Institut d'Estudis Catalans.

GARCÍA SEBASTIANI, M. (2004), “Crear identidades y proyectar políticas de España en la Argentina en tiempos de transformación del liberalismo. El Diario Español de Buenos Aires (1905-1912)", en Estudios Migratorios Latinoamericanos, A. 18, N. 55, diciembre, pp.525-554.

IRURZUN, J. (2017), "Redes de sociabilidad artística y cultural. El activismo de los catalanes de Buenos Aires (Argentina, inicios del siglo XX)", en REGUERA, A. (dir.), Vínculos que configuran redes. Las dimensiones relacionales de lo social y sus articulaciones a escalas diferenciadas, Buenos Aires, Teseo, pp.219-244.

JENSEN, S. (2010), "La comunidad catalana en Argentina al arribo de los exiliados de 1939: tensiones y debates en el mantenimiento de la unidad nacional", en Estudios Migratorios Latinoamericanos, A. 24, N. 69, julio-diciembre, pp.413-436.

LUCCI, M. (2009), El activismo patriótico de los "catalanes de América" de Buenos Aires: desde 1916 hasta el final del Casal Català, Tesis de doctorado, Universitat Autònoma de Barcelona, Facultat de Filosofia i Lletras.

- (2008), “La bandera de los 'catalanes de América': un ensayo de organización desde el exilio", en Cuadernos de Historia de España, Buenos Aires, Vol. 82, pp.191-212.

LLOBERA, J. (2003), De Catalunya a Europa. Fonaments de la identitat nacional, Barcelona, Anagrama-Empúries.

MANENT, A. (1989), La literatura catalana à l'exili, 2ạ. edición, Barcelona, Curial.

MORALES I MONTOYA, M.-SOBREQUÉS I CALLICÓ, J. (2012), "Introducció", a ROVIRA I VIRGILI, A., Sobre historia de Catalunya. Escrits de l'exili (1939-1949), Valls, Cosetània Edicions, pp.5-26.

OTEIZA, B. (2012), Le Courrier de la Plata. Un diario republicano francés en el Río de la Plata, Madrid, EAE. 
PLA BRUGAT, D. (1999), Els exiliats catalans. Un estudio sobre la emigración republicana española en México, México D.F., Instituto Nacional de Antropología e HistoriaOrfeó Català de Méxic.

ROCAMORA, J. (1992), Catalanes en la Argentina. En el centenario del Casal de Catalunya, Buenos Aires, El Fénix.

SEGURA, A.-SOLÉ i SABATÉ, J.M. (dirs.) (2008), Catalunya al món. La presència catalana al món, segles XIX i XX, Generalitat de Catalunya, Barcelona.

SERGI, P. (2012), Patria di carta. Storia di un quotidiano coloniale e del giornalismo italiano in Argentina, Cosenza, Pellegrini Editore.

UCELAY-DA CAL, E. (2018), Breve historia del separatismo catalán, Barcelona, Edicions B. 